\title{
Dose Regimen Rationale for Panitumumab in Cancer Patients: To Be Based on Body Weight or Not
}

This article was published in the following Dove Press journal: Clinical Pharmacology: Advances and Applications

\author{
Michael Z Liao' \\ Marloes Berkhout ${ }^{2}$ \\ Hans Prenen ${ }^{3}$ \\ Sandeep Dutta ${ }^{4}$ \\ Vijay V Upreti (iD) \\ 'Clinical Pharmacology, Modeling \& \\ Simulation, Amgen Inc., South San \\ Francisco, CA, USA; ${ }^{2}$ Medical \\ Development, Amgen B.V, Breda, the \\ Netherlands; ${ }^{3}$ Department of Medical \\ Oncology, University Hospital Antwerp, \\ Edegem, Belgium; ${ }^{4}$ Clinical Pharmacology, \\ Modeling \& Simulation, Amgen Inc. \\ Thousand Oaks, CA, USA
}

Introduction: Body weight can affect exposure, safety and efficacy of antibody-based therapies; sometimes these effects may not be clinically relevant. Panitumumab is approved for wild-type $R A S$ metastatic colorectal cancer, using a body weight-based dosing regimen. Recently, a report cited fixed-dose usage of panitumumab, rather than approved body weight-based dosing. The current work evaluates optimal dosing regimen scientifically based on clinical data, modeling and simulation. Herein, we assessed the effect of fixed and body weight-based dosing on panitumumab pharmacokinetics to determine which approach resulted in the least interpatient pharmacokinetic variability.

Patients and Methods: From the Vectibix program, 352 patients enrolled in three studies were evaluated; they had received panitumumab (body weight-based dose: $6 \mathrm{mg} / \mathrm{kg}$ every 2 weeks) and had pharmacokinetic (maximum serum $\left[\mathrm{C}_{\max }\right]$ and trough $\left[\mathrm{C}_{\min }\right]$ concentrations) and body weight data available. Additionally, concentration-time profiles at fixed (480 mg) and body weight-based doses $(6 \mathrm{mg} / \mathrm{kg})$ were simulated using a population pharmacokinetics model developed from 1200 patients.

Results: After administration of panitumumab $6 \mathrm{mg} / \mathrm{kg}, \mathrm{C}_{\max }$ and $\mathrm{C}_{\min }$ increased with increasing body weight; the mean $\mathrm{C}_{\max }$ and $\mathrm{C}_{\min }$ for patients weighing $<65 \mathrm{~kg}$ (lower quartile) were $23 \%$ and $30 \%$ lower, respectively, than for those weighing $>88 \mathrm{~kg}$ (upper quartile). The simulated area under the concentration-time curve (AUC) data also indicated that overall panitumumab exposure increased with increasing body weight for the body weight-based regimen. When AUC was simulated for a fixed dose (480 mg), the opposite effect was observed. Over the range of body weights, interpatient variability in simulated AUC was lower for the weight-based dose (29\%) than for the fixed dose (34\%).

Conclusion: Results demonstrate that the weight-based dose $(6 \mathrm{mg} / \mathrm{kg})$ reduced variability in panitumumab exposure across the range of body weights compared with the fixed-dose approach, indicating that a body weight-based approach is the recommended patient dosing strategy.

Keywords: panitumumab, pharmacokinetics, dose-exposure relationship, body weight, area under the curve, colorectal neoplasms

\section{Introduction}

Ideal dosing strategies provide minimal interpatient variability, optimizing therapeutic outcomes. ${ }^{1}$ Body weight can have an effect on exposure, safety, and efficacy for antibody-based therapies. Dosages are often prescribed based on body weight when these effects are clinically relevant. ${ }^{1}$ Although there is no consensus for whether an investigational biologic dose should be fixed or body weight-based
Correspondence: Vijay V Upreti Simulation, Amgen Inc., I I 20 Veteran Boulevard, South San Francisco, CA 94080 , USA

Fax + | 650-837-942 I

Email vupreti@amgen.com 
for first-in-human trials, it is recommended by the US Food and Drug Administration (FDA) that a full assessment of pharmacokinetics and pharmacodynamics be undertaken to reduce interpatient variability and assess optimal dosing to improve efficacy and safety. ${ }^{1}$

Panitumumab (Vectibix ${ }^{\circledR}$; Amgen Inc., Thousand Oaks, CA, USA; www.amgen.com), a human monoclonal antibody targeting the epidermal growth factor receptor (EGFR), has demonstrated efficacy in wild-type $R A S$ metastatic colorectal cancer $(\mathrm{mCRC}){ }^{2,3}$ The approved body weight-based dosing regimen of $6 \mathrm{mg} / \mathrm{kg}$ every 2 weeks (Q2W) was supported by scientific clinical study. ${ }^{4,5}$ Panitumumab pharmacokinetics are characterized by a 2-compartment model with linear and nonlinear clearance $^{6}$ and a volume of distribution (Vd) of approximately $40 \mathrm{~mL} / \mathrm{kg}$, consistent with saturable binding to EGFR. ${ }^{7}$ Additionally, panitumumab exposure increased proportionally between 2 and $6 \mathrm{mg} / \mathrm{kg}^{7}$

For some biologics, such as panitumumab, body weight-based dosing is necessary to achieve efficacy and safety after thorough dose optimization; ${ }^{8,9}$ however, it has been suggested that a fixed-dose approach may be used, rather than the label of body weight-based dosing. ${ }^{8,9}$ Hendrikx et al recommended panitumumab doses of 300 and $500 \mathrm{mg}$ Q2W for patients weighing 40-80 and 80-140 kg, respectively, instead of the approved body weight-based regimen. ${ }^{9}$

The objective of this analysis was to assess the effect of body weight on panitumumab pharmacokinetics in order to evaluate whether a fixed dose would reduce interpatient variability compared with the FDA-approved body weightbased dosing. Data from 352 patients receiving panitumumab at body weight--based dosing (6 mg/kg Q2W) with pharmacokinetic data (maximum observed serum concentration $\left[\mathrm{C}_{\max }\right]$, minimum [trough] observed concentration $\left[\mathrm{C}_{\min }\right]$ ), and recorded body weight available from three clinical trials (NCT00089635, NCT00083616, NCT00113763) were evaluated. Additionally, using the published pharmacokinetic model for panitumumab, ${ }^{6}$ simulation was performed to evaluate the variability of panitumumab area under the concentration versus time curve (AUC) over the dosing interval $\left(\mathrm{AUC}_{\mathrm{tau}}\right)$ using the fixed-dose approach versus the recommended body weight-based dose.

\section{Patients and Methods}

The study protocols for the three clinical trials assessed were approved by the appropriate institutional review boards and independent ethics committees at participating study centers and were conducted in accordance with the Declaration of Helsinki (Supplemental Table S1). All patients in these studies provided written informed consent prior to the initiation of the respective studies. All studies included in our analysis were published, multicenter, openlabel trials evaluating panitumumab $6 \mathrm{mg} / \mathrm{kg}$ Q2W in patients with mCRC. ${ }^{10,11}$ Patients with available $\mathrm{C}_{\max }$ and $\mathrm{C}_{\min }$ and a recorded body weight were included in the analysis; demographic data were also collected. For patients with pharmacokinetic data available and a recorded body weight at baseline, concentration-time profiles were determined on the basis of actual patient data.

In addition, concentration-time profiles were simulated using a fixed dose and the approved body weight-based dose from a previously published population pharmacokinetics model developed based on approximately 1200 patients. ${ }^{6}$ The fixed dose used for the simulation was selected based on median baseline body weight across the clinical studies and the approved body weight-based dose $(6 \mathrm{mg} / \mathrm{kg}){ }^{7}$ Based on a median body weight of $80 \mathrm{~kg}$ and the approved panitumumab dose of $6 \mathrm{mg} / \mathrm{kg}$, a fixed dose of $480 \mathrm{mg}$ was used for the simulation.

The population pharmacokinetic model used for the simulation was a 2-compartment model with parallel linear and nonlinear clearance. The error model included both proportional and additive error, which improved the model substantially versus models with only proportional or additive error. The final model estimated that for a typical 60-year-old male patient with mCRC weighing $80 \mathrm{~kg}$ (the approximate median body weight of patients included the model), estimates for the linear clearance, the maximum nonlinear clearance (maximum elimination rate $[\mathrm{Vmax}] /$ Michaelis-Menten constant $[\mathrm{Km}])$, the central volume of distribution $\left(\mathrm{V}_{1}\right)$, peripheral volume of distribution $\left(\mathrm{V}_{2}\right)$ and the Km were 0.273 $\mathrm{L} / \mathrm{d}, 28.4 \mathrm{~L} / \mathrm{d}, 3.95 \mathrm{~L}, 2.59 \mathrm{~L}$ and $0.426 \mu \mathrm{g} / \mathrm{mL}$, respectively. Final model covariates included body weight, sex, and cancer type on clearance, body weight and age on $\mathrm{Vmax}$, and body weight and sex on central $\mathrm{V}_{1}$. Using the final model, panitumumab pharmacokinetic profiles were generated for 1000 virtual patients by Monte Carlo simulation of fixed dose (480 mg) Q2W and body weight-based dose (6 mg/kg) Q2W, using body weights reflective of body weights across the patient population in the three clinical trials. ${ }^{10,11}$ $\mathrm{AUC}_{\text {tau }}$ was calculated using noncompartmental analysis from the simulated pharmacokinetic profiles, using 
Table I Demographics and Baseline Characteristics of All Enrolled Patients Assigned to Panitumumab from Three Clinical Trials

\begin{tabular}{|c|c|c|c|}
\hline & Median & Mean (SD) & n (\%) \\
\hline \multicolumn{4}{|l|}{ Age } \\
\hline Male & 63.0 & $61.7(10.5)$ & $360(58.2)$ \\
\hline Female & 59.0 & $59.3(10.4)$ & $259(41.8)$ \\
\hline \multicolumn{4}{|l|}{ Body weight } \\
\hline Male & 81.8 & $82.7(17.0)$ & $360(58.2)$ \\
\hline \multicolumn{4}{|l|}{ Race/ethnicity } \\
\hline White & 81.4 & $82.1(16.5)$ & $320(5 \mathrm{I} .7)$ \\
\hline Black & 92.6 & $89.2(20.0)$ & $21(3.4)$ \\
\hline Hispanic & 76.4 & $85.2(19.8)$ & $13(2.1)$ \\
\hline Asian & 71.0 & $71.0(15.0)$ & $2(0.3)$ \\
\hline Other ${ }^{a}$ & 104.1 & $99.9(17.3)$ & $4(0.6)$ \\
\hline Female $^{b}$ & 65.0 & $69.2(19.1)$ & $258(41.7)$ \\
\hline \multicolumn{4}{|l|}{ Race/ethnicity } \\
\hline White & 65.0 & $69.3(19.8)$ & $203(32.8)$ \\
\hline Black & 65.5 & $68.9(17.8)$ & $29(4.7)$ \\
\hline Hispanic & 68.4 & $71.3(16.1)$ & $20(3.2)$ \\
\hline Asian & 55.3 & $59.2(8.1)$ & $5(0.8)$ \\
\hline Other ${ }^{\mathrm{a}}$ & 58.2 & $58.2(0)$ & $\mathrm{I}(0.2)$ \\
\hline \multicolumn{4}{|l|}{ Sex } \\
\hline Male & - & - & $360(58.2)$ \\
\hline Female & - & - & $259(41.8)$ \\
\hline Race/ethnicity & - & - & \\
\hline White & - & - & $524(84.7)$ \\
\hline Black & - & - & $50(8.1)$ \\
\hline Hispanic & - & - & $33(5.3)$ \\
\hline Asian & - & - & $7(1.1)$ \\
\hline Other ${ }^{a}$ & - & - & $5(0.8)$ \\
\hline
\end{tabular}

Notes: a'Other includes all race categories other than White, Black, Hispanic and Asian; ${ }^{\mathrm{b} E t h n i c i t y ~ n o t ~ a v a i l a b l e ~ f o r ~ I ~ f e m a l e ~ p a t i e n t . ~}$

linear trapezoidal integration as a method of estimation. Interpatient variability was determined for all pharmacokinetic parameters.

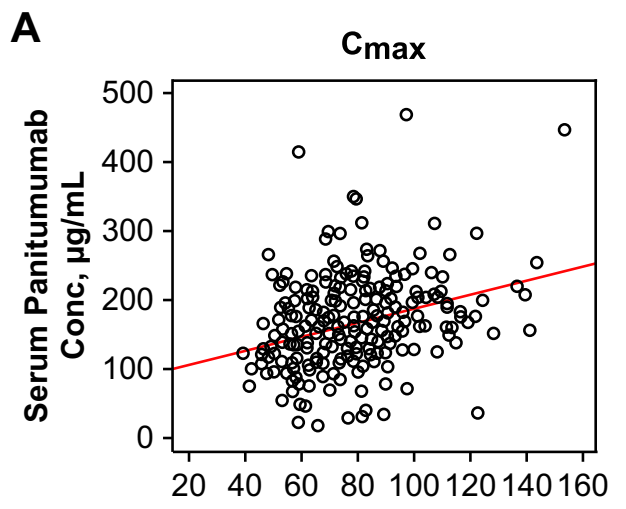

Body Weight, kg

\section{Results}

Of the 619 patients enrolled in the three studies and assigned to panitumumab, a total of 352 patients received panitumumab at body weight-based dosing of $6 \mathrm{mg} / \mathrm{kg}$ Q2W and had pharmacokinetic and body weight data available. Demographic data for all 619 patients are shown in Table 1. After administration of panitumumab, $\mathrm{C}_{\max }$ and $\mathrm{C}_{\min }$ increased with increasing body weight (Figure $1 \mathrm{~A}$ and $\mathrm{B}$ ). The mean $\mathrm{C}_{\max }$ and $\mathrm{C}_{\min }$ for patients weighing $<65 \mathrm{~kg}$ (lower quartile) were $23 \%$ and $30 \%$ lower, respectively, than for those weighing $>88 \mathrm{~kg}$ (upper quartile). For lower versus upper body weight quartiles, mean $C_{\max }$ was 143 versus 187 $\mu \mathrm{g} / \mathrm{mL}$; mean $\mathrm{C}_{\min }$ was 27 versus $38 \mu \mathrm{g} / \mathrm{mL}$. The variability contributed from body weight was lower than observed total variability (37-59\%).

Using population pharmacokinetic modeling and simulation, the simulated $\mathrm{AUC}_{\mathrm{tau}}$ data indicated that, overall, panitumumab exposure increased with increasing body weight with weight-based dosing (Figure 2A). For the fixed dose $(480 \mathrm{mg})$, the opposite effect was observed; overall, panitumumab exposure decreased with increasing body weight (Figure 2B).

Over the wide range of patient body weights, the total variability in simulated $\mathrm{AUC}_{\text {tau }}$ was lower for the weightbased dose (29\%) than for the fixed dose (34\%; Table 2), as expected. Additionally, the difference in median $\mathrm{AUC}_{\text {tau }}$ between patients with body weight in upper and lower quartiles was smaller for weight-based (40\%) than fixed (80\%) dosing.

\section{Discussion}

The most appropriate dosing regimen for individual monoclonal antibodies is variable and dependent on

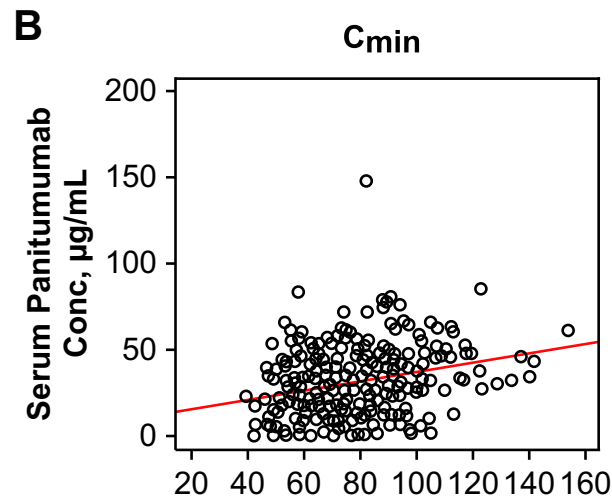

Body Weight, kg

Figure I (A) $\mathrm{C}_{\max }$ and (B) $\mathrm{C}_{\min }$ concentration of serum panitumumab versus body weight for patients in clinical trials receiving panitumumab 6 mg/kg $\mathrm{Q} 2 \mathrm{~W}$. Abbreviations: $C_{\max }$, maximum observed concentration; $C_{\min }$, minimum observed concentration; Conc, concentration; Q2W, every 2 weeks. 
A

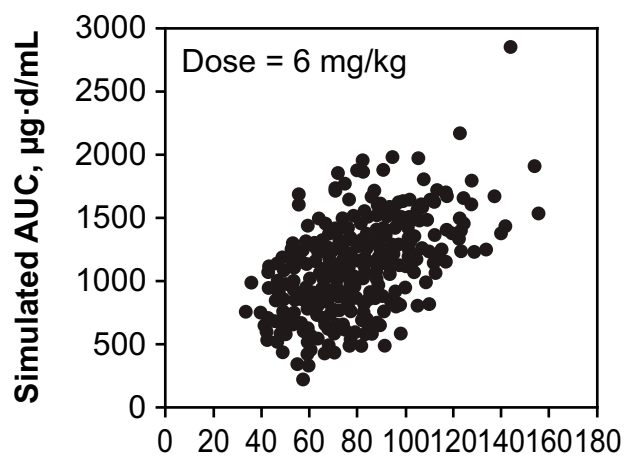

Body Weight, kg
B

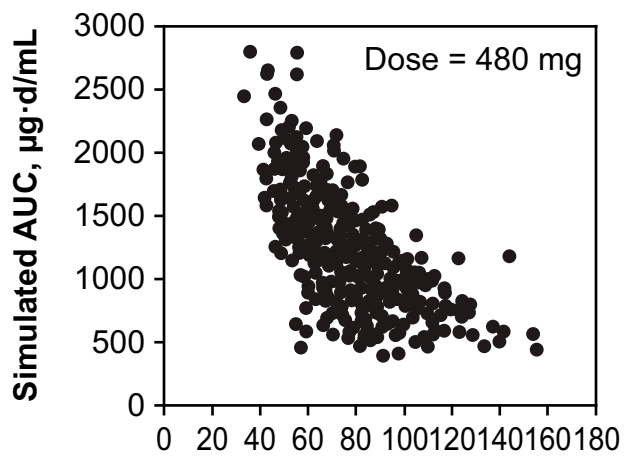

Body Weight, kg

Figure 2 Simulated $\mathrm{AUC}_{\text {tau }}$ values for 1000 patients modeled to receive panitumumab at $(\mathbf{A})$ body weight-based dose $(6 \mathrm{mg} / \mathrm{kg})$ and $(\mathbf{B})$ fixed dose $(480 \mathrm{mg})$ based on the published population pharmacokinetic model. ${ }^{6}$

Abbreviation: $\mathrm{AUC}_{\mathrm{tau}}$, area under the concentration versus time curve over the dosing interval.

the effect of factors such as body weight on the pharmacokinetics of the monoclonal antibody. ${ }^{12}$ The FDA recommends that a full assessment of pharmacokinetics be undertaken to reduce interpatient variability in drug exposure with a view to optimizing dosing and improving efficacy and safety. ${ }^{1}$ Based on the results of Phase 3 studies, panitumumab was approved as a body weightbased dose regimen for the treatment of mCRC. ${ }^{4}$ However, it is suggested that a fixed-dose approach has practical advantages in clinical practice; ${ }^{12}$ for example, a fixed dose may simplify dose administration, streamline compounding and reduce medication error. ${ }^{8,9}$ Fixed doses of panitumumab are not FDA approved, but have been suggested ${ }^{9}$ therefore, we assessed the body weight-based variability in exposure to the body weight-adjusted dose $(6 \mathrm{mg} / \mathrm{kg})$ across three clinical trials, and compared the FDA-approved body weight-based dosing with a fixed-dose approach in a simulated model.
In our analysis of pharmacokinetic data from clinical trials using body weight-based dosing, $\mathrm{C}_{\max }$ and $\mathrm{C}_{\min }$ increased with increasing body weight. In the simulation, the weight-based dose $(6 \mathrm{mg} / \mathrm{kg})$ led to substantially less variability in panitumumab exposure across the range of body weights than did fixed dosing (480 mg), supporting the premise that a body weight-based approach leads to less variability in drug exposure across patients. ${ }^{8}$

A population pharmacokinetic model of panitumumab was developed using serum concentration data from 1200 patients and 14 clinical studies. This analysis found that body weight, age, sex, and cancer type contributed to interindividual variability in panitumumab pharmacokinetics. However, age, sex, and cancer type were found to contribute only minimally to the total variability in panitumumab exposure (using $\mathrm{AUC}_{\mathrm{ss}}$ as the indicator); ${ }^{6}$ therefore, dose adjustments based on these covariates are considered unnecessary. ${ }^{7}$ In contrast, body weight made the greatest contribution to interpatient variability; when

Table 2 Simulated AUC ${ }_{\text {tau }}$ Values for Patients Modeled to Receive Panitumumab Q2W as a Fixed or Body Weight-Based Dose

\begin{tabular}{|c|c|c|c|c|c|}
\hline Dose & Mean AUC $C_{\text {tau }}$ ug $\mathrm{d} / \mathrm{mL}(95 \% \mathrm{Cl})$ & CV, \% & Low BW BW $^{2}$ & High BW' & Ratio $^{c}$ \\
\hline $480 \mathrm{mg}^{\mathrm{d}, \mathrm{e}}$ & $1216(1189-1243)$ & 34 & 1582 & 897 & 1.8 \\
\hline $6 \mathrm{mg} / \mathrm{kg}^{\mathrm{e}}$ & $1093(1073-1112)$ & 29 & 908 & 1254 & 1.4 \\
\hline
\end{tabular}

Notes: ${ }^{a}$ Low BW represents the median $A \cup C_{\text {tau }}$ for patients with body weight in the lower quartile; ${ }^{\text {b High }} \mathrm{BW}_{\text {represents the median }} \mathrm{AUC} \mathrm{C}_{\text {tau }}$ for patients with body weight in the upper quartile; ' $R$ atio for AUC values for the low BW and high BW groups; the greater value is divided by the lesser value; ${ }^{\mathrm{d}}$ Fixed dose was calculated based on $6 \mathrm{mg} / \mathrm{kg} \times 80 \mathrm{~kg}$ (the approximate median body weight in the population); ${ }^{e}$ Panitumumab pharmacokinetic profiles were generated for 1000 virtual patients by Monte Carlo simulation of fixed dose (480 mg) Q2W and body weight-based dose (6 mg/kg) Q2W; AUC $\mathrm{tau}_{\text {was }}$ calculated using noncompartmental analysis from the simulated pharmacokinetic profiles.

Abbreviations: $\mathrm{AUC}_{\text {tau }}$, area under the concentration versus time curve over the dosing interval; $\mathrm{BW}$, body weight; $\mathrm{Cl}$, confidence interval; $\mathrm{CV}$, coefficient of variation; Q2W, every 2 weeks. 
expressed as the log-transformed $\mathrm{AUC}_{\mathrm{ss}}$, the body weightbased dose regimen reduced the total variance in exposure by $69.2 \% .{ }^{6}$ Moreover, when considering pharmacokinetic variability in this analysis, $97 \%$ of all patients treated with panitumumab $6 \mathrm{mg} / \mathrm{kg}$ Q2W had steady-state $\mathrm{C}_{\min }>3.83$ $\mu \mathrm{g} / \mathrm{mL}$, indicating panitumumab remained above pharmacologically meaningful concentrations. ${ }^{7}$ This provides further support that dosing based on body weight is reasonable and adequate.

Body mass index, body surface area, lean body mass, or ideal body weight have been proposed as alternative parameters for body size-adjusted dosing. Although lean body mass accounts for less variability in $\mathrm{AUC}_{\mathrm{ss}}$ than body weight, ${ }^{6}$ body weight is preferable because it is more conveniently obtained clinically. ${ }^{6}$ Other body size measurements would require imputation, ${ }^{6}$ and have the potential to contribute to dosing error.

Data from clinical trials and from pharmacokinetic simulations indicate that the approved body weightbased dosing (6 mg/kg Q2W) results in less variability in panitumumab exposure across patient body weights than does a fixed dose. Exposure-response analysis may also be used to support body weight-based dosing; however, in the three studies supporting the efficacy of monotherapy, the first blood sample to assess panitumumab serum concentration was not collected until week 7. Approximately one-quarter of patients had discontinued panitumumab before week 7 of the study and did not have any pharmacokinetic data available. The lack of pharmacokinetic data available for patients who discontinue early may lead to bias in any traditional attempt to model effectiveness as a function of pharmacokinetics. Thus, there appears to be no feasible way to conduct an analysis of these data without introducing survivor bias. Nonetheless, it is expected that less variability in panitumumab exposure would be beneficial in terms of clinical outcomes. Importantly, body weight-based dosing was approved by the FDA based on the efficacy and safety associated with panitumumab in clinical trials; ${ }^{4}$ any proposal to change the dosing approach would need a full assessment of efficacy and safety, including an assessment of practical benefits resulting from the simplified approach to dose administration.

\section{Conclusions}

In conclusion, the approved body weight-based dosing for panitumumab of $6 \mathrm{mg} / \mathrm{kg}$ Q2W regimen was supported by scientific clinical study data and pharmacokinetic modeling and simulations to provide optimal panitumumab exposure over the range of body weights of patients receiving the drug in clinical trials, suggesting this dose regimen would provide optimal clinical benefit.

\section{Abbreviations}

$\mathrm{AUC}$, area under the concentration-time curve; $\mathrm{AUC}_{\mathrm{SS}}$, area under the concentration-time curve at steady-state; $\mathrm{AUC}_{\text {tau }}$, area under the concentration-time curve at steady-state over the dosing interval; BW, body weight; CI, confidence interval; $\mathrm{C}_{\max }$, maximal (peak) observed serum concentration; $\mathrm{C}_{\min }$, minimum (trough) observed serum concentration; $\mathrm{CV}$, coefficient of variation; EGFR, epidermal growth factor receptor; FDA, US Food and Drug Administration; Km, Michaelis Menten constant; mCRC, metastatic colorectal cancer; Q2W, every 2 weeks; $\mathrm{V}_{1}$, central volume of distribution; $\mathrm{V}_{2}$, peripheral volume of distribution; $\mathrm{Vd}$, volume of distribution; Vmax, maximum velocity.

\section{Data Sharing Statement}

Qualified researchers may request data from Amgen clinical studies. Complete details are available at the following: http://www.amgen.com/datasharing.

\section{Acknowledgments}

The authors thank Lee B. Hohaia, PharmD, CMPP (ICON, North Wales, PA), whose work was funded by Amgen Inc., for medical writing assistance in the preparation of this manuscript.

\section{Author Contributions}

All authors made substantial contributions to conception and design, acquisition of data, or analysis and interpretation of data; took part in drafting the article or revising it critically for important intellectual content; agreed to submit to the current journal; gave final approval of the version to be published; and agree to be accountable for all aspects of the work.

\section{Funding}

This analysis was funded by Amgen Inc.

\section{Disclosure}

The study was funded by Amgen Inc. Michael Z. Liao is an employee of and stockholder in Amgen. Marloes Berkhout is an employee of Amgen B.V. and has restricted shares in Amgen. Hans Prenen has received honoraria and/or travel grants from Amgen, Bayer, Ipsen, Lilly, Merck, Novartis, Pfizer, Roche, Sanofi, Terumo, and Vifor pharma. Sandeep 
Dutta is an employee of and stockholder in Amgen. Vijay V. Upreti is an employee of and stockholder in Amgen. The authors report no other conflicts of interest in this work.

\section{References}

1. Zhao L, Ren TH, Wang DD. Clinical pharmacology considerations in biologics development. Acta Pharmacol Sin. 2012;33(11):1339-1347. doi:10.1038/aps.2012.51

2. Douillard J-Y, Siena S, Tabernero J, et al. Overall survival (OS) analysis from PRIME: randomized phase III study of panitumumab (pmab) with FOLFOX4 for first-line metastatic colorectal cancer (mCRC). J Clin Oncol. 2013;31:abstract3620. doi:10.1200/ jco.2013.31.15_suppl.3620

3. Kim TW, Elme A, Kusic Z, et al. A phase 3 trial evaluating panitumumab plus best supportive care vs best supportive care in chemorefractory wild-type KRAS or RAS metastatic colorectal cancer. $\mathrm{Br}$ $J$ Cancer. 2016;115(10):1206-1214. doi:10.1038/bjc.2016.309

4. Vectibix ${ }^{\circledR}$ (panitumumab). Full prescribing information. Thousand Oaks, CA: Amgen Inc; 2017.

5. Vectibix (panitumumab). Summary of product characteristics. Breda, Netherlands: Amgen Europe B.V; 2018.

6. Ma P, Yang BB, Wang YM, et al. Population pharmacokinetic analysis of panitumumab in patients with advanced solid tumors. J Clin Pharmacol. 2009;49(10):1142-1156. doi:10.1177/0091270009344989
7. Yang BB, Lum P, Chen A, et al. Pharmacokinetic and pharmacodynamic perspectives on the clinical drug development of panitumumab. Clin Pharmacokinet. 2010;49(11):729-740. doi:10.2165/11535970-000000000-00000

8. Wang DD, Zhang S, Zhao H, Men AY, Parivar K. Fixed dosing versus body size-based dosing of monoclonal antibodies in adult clinical trials. J Clin Pharmacol. 2009;49(9):1012-1024. doi: $10.1177 / 0091270009337512$

9. Hendrikx J, Haanen J, Voest EE, Schellens JHM, Huitema ADR, Beijnen JH. Fixed dosing of monoclonal antibodies in oncology. Oncologist. 2017;22(10):1212-1221. doi:10.1634/theoncologist.2017-0167

10. Hecht JR, Mitchell E, Neubauer MA, et al. Lack of correlation between epidermal growth factor receptor status and response to panitumumab monotherapy in metastatic colorectal cancer. Clin Cancer Res. 2010;16(7):2205-2213. doi:10.1158/1078-0432.CCR09-2017

11. Van Cutsem E, Peeters M, Siena S, et al. Open-label phase III trial of panitumumab plus best supportive care compared with best supportive care alone in patients with chemotherapy-refractory metastatic colorectal cancer. J Clin Oncol. 2007;25(13):1658-1664. doi:10.1200/JCO.2006.08.1620

12. Bai S, Jorga K, Xin Y, et al. A guide to rational dosing of monoclonal antibodies. Clin Pharmacokinet. 2012;51(2):119-135. doi:10.2165/ 11596370-000000000-00000

\section{Publish your work in this journal}

Clinical Pharmacology: Advances and Applications is an international, peer-reviewed, open access journal publishing original research, reports, reviews and commentaries on all areas of drug experience in humans. The manuscript management system is completely online and includes a very quick and fair peer-review system, which is all easy to use. Visit http://www.dovepress.com/testimonials.php to read real quotes from published authors. 